\title{
The paradox role of cytotoxic T-lymphocytes in NAFLD-associated hepatocellular carcinoma
}

\author{
Emanuele Albano", Salvatore Sutti" \\ Department of Health Sciences and Interdisciplinary Research Centre for Autoimmune Diseases, University of Eastern Piedmont, Novara, Italy \\ "These authors contributed equally to this work. \\ Correspondence to: Prof. Emanuele Albano. Department of Health Sciences, University of Eastern Piedmont, Via Solaroli 17, 28100 Novara, Italy. \\ Email: emanuele.albano@med.uniupo.it. \\ Comment on: Pfister D, Núñez NG, Pinyol R, et al. NASH limits anti-tumour surveillance in immunotherapy-treated HCC. Nature 2021;592:450-6.
}

Submitted Jun 16, 2021. Accepted for publication Jun 28, 2021.

doi: 10.21037/hbsn-21-243

View this article at: https://dx.doi.org/10.21037/hbsn-21-243

Nonalcoholic fatty liver disease (NAFLD) is already the fastest growing cause of hepatocellular carcinoma (HCC) in several countries (1). Despite the incidence of NAFLDrelated HCC is still lower than that of HCCs associated to viral infections, its prevalence is expected to increase in the next years concomitantly with the growing diffusion of overweight and obesity (1). Current view sees chronic hepatic inflammation as the driving force in the evolution of NAFLD to liver fibrosis/cirrhosis as well as in the development of HCC. In this setting, available evidence indicates that beside innate immunity also adaptive immune responses play an important role in supporting hepatic inflammation (2). Particularly, several studies have implicated liver cytotoxic CD8 ${ }^{+}$T-lymphocytes as important players in supporting the evolution of nonalcoholic steatohepatitis (NASH) showing that $\mathrm{CD}^{+}$T-cell ablation effectively ameliorates steatohepatitis and reduces HCC prevalence in mice receiving high fat diets $(3,4)$. Nonetheless, the actual role of these cells in the processes leading to HCC is less obvious since tumor infiltrating $\mathrm{CD}^{+} \mathrm{T}$-lymphocytes also perform important anti-tumoral actions, which need to be overcome to allow cancer cell growth (5).

The recent paper by Pfister and co-workers (6) sheds some light on these inconsistencies by showing that depleting CD8 ${ }^{+}$T-cells in mice following the onset of NASH, but prior to HCC development, effectively reduced both liver damage and HCC incidence. Single-cell mapping of these $\mathrm{CD} 8^{+} \mathrm{T}$-cells revealed that they were characterized by markers of activation/exhaustion and by a high expression the immunomodulating molecule programmed cell death protein
1 (PD1). An enhanced expression of PD1 ligand PDL1 was instead evident in hepatocytes. Despite the high prevalence of $\mathrm{CD}^{+} / \mathrm{PD}^{+}{ }^{+}$T-cells in NAFLD-driven HCCs the authors observed that these tumours did not respond to anti-PD1 therapy and that such a treatment rather caused an earlier HCC onset along with the worsening NASH evolution to fibrosis. A similar behaviour was also evident in PD1deficient mice (6) and was in contrast with previous reports showing the effectiveness of anti-PD1 agents in promoting tumour regression in non-NAFLD HCC models (7). Interestingly, liver tumours from anti-PD1-treated mice contained an increased number of $\mathrm{CD} 8^{+} / \mathrm{PD} 1^{+} \mathrm{T}$-cells that, as compared to liver resident $\mathrm{CD} 8^{+} \mathrm{T}$-cells, were characterized by an increased expression of effector and exhaustion markers and a defective proliferative capability. These data suggested that $\mathrm{CD} 8^{+} / \mathrm{PD} 1^{+} \mathrm{T}$-cells lacked immune-surveillance functions and had instead a tissuedamaging action, which was partially counteracted by PD1 signalling, thus explaining the unfavourable effects of antiPD1 agents in NASH evolution and HCC development (6). Beside these experimental observations, Pfister and coworkers also investigated $\mathrm{CD} 8^{+} \mathrm{T}$-cell phenotype in liver biopsies from NASH patients and healthy controls showing that human NAFLD/NASH livers were enriched for $\mathrm{CD}^{+} /$ $\mathrm{PD} 1^{+} \mathrm{T}$-cells with a gene expression profile similar to that observed in rodent NASH (6). Furthermore, a metaanalysis of three phase III clinical trials evaluating the outcome of immunotherapies targeting PD1 or PDL1 in about 1,600 patients with advanced HCC demonstrated that, despite immunotherapy improved the overall survival 
in the whole population, such a benefit only involved the patients with HCC of viral origin. In more detail, the patients with NAFLD-associated HCCs had significantly shorter overall survival after immunotherapy than patients with other underling aetiologies (6). Although the number of patients in the NAFLD/NASH-HCC cohorts was small and the study requires further validation, this observation confirms the clinical relevance of the experimental data and suggests that the presence of liver steatosis/steatohepatitis specifically activates $\mathrm{CD} 8^{+} / \mathrm{PD} 1^{+} \mathrm{T}$-cells in a manner that favours the disease evolution and limits the response to HCC immunotherapy. The authors also hypothesized that overweigh patients with concomitant cancer at other organs might be at risk for liver damage in response to anti-PD1 immunotherapy.

At present, the factors that promote the recruitment and activation of $\mathrm{CD} 8^{+} / \mathrm{PD}^{+}{ }^{+} \mathrm{T}$-cells in $\mathrm{NASH}$ are poorly characterized. Previous studies have shown that liver T-cells in NASH recognize epitopes generated by oxidative stress and that oxidative stress-mediated immune responses drive hepatic inflammation in NASH (8). Recently, in a parallel paper the same group has shown that metabolic stimuli involving acetate and ATP induce $\mathrm{CD}^{+} / \mathrm{CXCR}^{+} /$ $\mathrm{PD}^{+}{ }^{+} \mathrm{T}$-cells to exert an antigen independent cytotoxic action toward hepatocytes (9). All together these findings point $\mathrm{CD} 8^{+} \mathrm{T}$-cells as important drivers of tissue injury and hepatic inflammation in NASH, thus explaining the protective action of $\mathrm{CD}^{+} \mathrm{T}$-cell ablation in preventing the disease evolution to HCC.

In conclusion, the work by Pfister and co-workers outlines the peculiar action of cytotoxic T-lymphocytes in NAFLD-associated HCC giving a possible biological explanation for the recent observation that about $13 \%$ of patients with advanced HCC receiving anti-PD-1 therapy show an enhanced tumour growth, a condition known as hyper-progressive syndrome (10). The results also indicate the importance of a better stratification of HCC patient undergoing immunotherapy according to the aetiology of liver cancer and stress the need of devising more specific immune treatments for NAFLD-related HCCs.

\section{Acknowledgments}

Funding: The research was supported by the University of Eastern Piedmont (grant FAR 2019) and Fondazione Cariplo Milan, Italy (grant 2017/0535).

\section{Footnote}

Provenance and Peer Review: This article was commissioned by the editorial office of Hepatobiliary Surgery and Nutrition. The article did not undergo external peer review.

Conflicts of Interest: Both authors have completed the ICMJE uniform disclosure form (available at https://hbsn. amegroups.com/article/view/10.21037/hbsn-21-243/coif). The authors have no conflicts of interest to declare.

Ethical Statement: The authors are accountable for all aspects of the work in ensuring that questions related to the accuracy or integrity of any part of the work are appropriately investigated and resolved.

Open Access Statement: This is an Open Access article distributed in accordance with the Creative Commons Attribution-NonCommercial-NoDerivs 4.0 International License (CC BY-NC-ND 4.0), which permits the noncommercial replication and distribution of the article with the strict proviso that no changes or edits are made and the original work is properly cited (including links to both the formal publication through the relevant DOI and the license). See: https://creativecommons.org/licenses/by-nc-nd/4.0/.

\section{References}

1. Huang DQ, El-Serag HB, Loomba R. Global epidemiology of NAFLD-related HCC: trends, predictions, risk factors and prevention. Nat Rev Gastroenterol Hepatol 2021;18:223-38.

2. Sutti S, Albano E. Adaptive immunity: an emerging player in the progression of NAFLD. Nat Rev Gastroenterol Hepatol 2020;17:81-92.

3. Wolf MJ, Adili A, Piotrowitz K, et al. Metabolic activation of intrahepatic CD8+ T cells and NKT cells causes nonalcoholic steatohepatitis and liver cancer via cross-talk with hepatocytes. Cancer Cell 2014;26:549-64.

4. Breuer DA, Pacheco MC, Washington MK, et al. CD8+ $T$ cells regulate liver injury in obesity-related nonalcoholic fatty liver disease. Am J Physiol Gastrointest Liver Physiol 2020;318:G211-24.

5. Ringelhan $\mathrm{M}$, Pfister $\mathrm{D}, \mathrm{O}^{\prime}$ Connor T, et al. The immunology of hepatocellular carcinoma. Nat Immunol 2018;19:222-32. 
6. Pfister D, Núñez NG, Pinyol R, et al. NASH limits antitumour surveillance in immunotherapy-treated HCC.

Nature 2021;592:450-6.

7. Chung AS, Mettlen M, Ganguly D, et al. Immune Checkpoint Inhibition is Safe and Effective for Liver Cancer Prevention in a Mouse Model of Hepatocellular Carcinoma. Cancer Prev Res (Phila) 2020;13:911-22.

8. Sutti S, Jindal A, Locatelli I, et al. Adaptive immune responses triggered by oxidative stress contribute

Cite this article as: Albano E, Sutti S. The paradox role of cytotoxic T-lymphocytes in NAFLD-associated hepatocellular carcinoma. HepatoBiliary Surg Nutr 2021;10(5):705-707. doi: 10.21037/hbsn-21-243 to hepatic inflammation in NASH. Hepatology 2014;59:886-97.

9. Dudek M, Pfister D, Donakonda S, et al. Auto-aggressive CXCR6 + CD8 T cells cause liver immune pathology in NASH. Nature 2021;592:444-9. Erratum in: Nature 2021;593:E14.

10. Kim CG, Kim C, Yoon SE, et al. Hyperprogressive disease during PD-1 blockade in patients with advanced hepatocellular carcinoma. J Hepatol 2021;74:350-9. 